\title{
CFD SIMULATION OF EROSION BY PARTICLE COLLISION IN U- BEND AND HELICAL TYPE PIPES
}

\author{
Mohammad Sheikh Mamoo $^{1}$, Ataallah Soltani Goharrizi ${ }^{1}$, Bahador Abolpour ${ }^{2 *}$ \\ ${ }^{1}$ Department of Chemical Engineering, Shahid Bahonar University of Kerman, Kerman, Iran \\ ${ }^{2}$ Department of Chemical Engineering, Sirjan University of Technology, Sirjan, Iran \\ E-mail: bahadorabolpor1364@yahoo.com \\ *corresponding author
}

\begin{abstract}
Erosion caused by solid particles in curve pipes is one of the major concerns in the oil and gas industries. Small solid particles flow with a carrier liquid fluid and impact the inner wall of the piping, valves, and other equipment. These components face a high risk of solid particle erosion due to the constant collision, which may result in equipment malfunctioning and even failure. In this study, the two-way coupled Eulerian-Lagrangian method with the Oka erosion and Grant and Tabakoff particle-wall rebound models approach is employed to simulate the liquid-solid flow in U-bend and helical pipes using computational fluid dynamics. The effects of operating parameters (inlet fluid velocity and temperature, particle density and diameter, and mass flow rate) and design parameters (mean curvature radius/pipe diameter ratio) are investigated on the erosion of these tubes walls. It is concluded that increasing the fluid velocity and temperature, particle mass flow and particle density increase the penetration rate, particle diameter affects the rate of penetration, and increasing mean curvature radius/pipe diameter ratio decreases the rate of penetration.
\end{abstract}

Keywords: Liquid-solid flow, U-bend pipe, helical pipe, solid particles erosion, CFD.

\section{Introduction}

Existing of solid particles in the fluid flows inside the pipes of gas and oil industries is inevitable. These particles cause several problems. One of the most important problems is the erosion of inside walls of pipelines, valves, and other equipment. Such unforeseen and uncontrolled flows decay the performance of this equipment and may destroy a component causing an unwanted shutdown in the production process (Solnordal and Wong 2015). Predicting this erosion is very complicated in multi-fluid flows due to the effects of various factors, such as the impact velocity and angle and also the particle size and physical properties, on this phenomenon (Pereira et al. 2014).

Researchers have investigated this type of erosion in different industries, such as navy, gas and oil, mineral, nuclear processes, and even in dental science. These studies improved the hindex of the issue to 46 in January 2016 (Burson-Thomas and Wood 2017). A wide range of erosion equations has been developed for various problems (Morsi and Alexander 1972; Gosman and Ioannides 1983) because, erosion is a complex phenomenon depending on several factors. 
Meng and Ludema (1995) concluded that there are four different mechanisms for this phenomenon. In addition to these mechanisms, it is observed that the particle velocity and impact angle are important factors in this area (Zhang et al. 2007). Finnie (1960) has presented one of the first equations for predicting the erosion rate of solid particles in fluid flows. Ahlert (1994) and McLaury (1996) obtained empirical constants of the Finnie equation (Finnie 1960) for stainless steel and aluminum walls, respectively. Salama (2000) presented an empirical model for a multi-phase fluid, which assumed the particles impact velocity equal to the fluid flow velocity for estimating the erosion rate. Mazumder et al. (2005) presented a numerical model for predicting the erosion in the multi-phase flows in elbow joints. They considered different velocities for the solid particles and gas and liquid flows. Fan et al. (2001) had a set of experimental and numerical studies on the erosion of solid particles in gas flows inside curved pipes. Chen et al. (2004) had a similar study for the multi-phase flows inside the elbow and tee joints. These studies presented an overall view of the erosion of solid particles inside the curved pipes. Zhang et al. (2007) used a laser Doppler velocimetry method to investigate the erosion of solid particles in water and air flows. They compared their observed results with the predictions of numerical simulations and concluded that the erosion/corrosion research center and Oka erosion models have suitable accordance with the empirical observations. Bozzini et al. (2003) developed a numerical simulation for the erosion of solid particles in a four-phase flow (two liquid phases, a gas phase, and solid particles). They investigated the effects of various factors, such as the fluid flow velocity and gas and particle volume fractions, on the erosion ratio of these particles on the stainless steel pipes. Zhang et al. (2012) had a numerical study for obtaining the location with maximum erosion for liquid-solid particles flow inside the elbow. They resulted that the fluid velocity is an important factor in the maximum erosion position inside this elbow. Jukai Chen et al. (2015) used the finite element method for computational fluid dynamics modeling of liquid-solid particles flows inside the $90 \mathrm{o}, 60 \mathrm{o}$, and 450 elbows. They resulted that the fluid velocity and also the elbow angle are important factors in the erosion rate of the walls of these joints. Duarte et al. (2015) investigated the effects of solid particles on erosion inside elbows, numerically.

In this study, a numerical model for simulating the erosion and penetration rates of solid particles in two different geometry of pipes, i.e. U-bend and helical pipes, has been developed. The Oka model has been utilized for investigating the erosion effects in different operating conditions of inlet fluid velocity and temperature, and inlet particles flowrate, size, and density. The effects of mean curvature radius/pipe diameter ratio (R/D) on the erosion and penetration rates of solid particles have been also investigated. These investigations identify the effective factors on the erosion rate of solid particles in the solid-liquid flows inside the curved pipes.

\section{Methodology}

First, two three-dimensional geometries, i.e. U-bend and helical pipes, have been defined as shown in Figure 1. Certain lengths of tubes have been considered at the inlet and outlet sections of these pipes for developing the fluid flow and removing the entrance and exit effects. The Ubend pipe has a $5 \mathrm{~cm}$ diameter, $1 \mathrm{~m}$ inlet and $60 \mathrm{~cm}$ outlet lengths, and a $75 \mathrm{~mm}$ curvature radius. The helical pipe has $45 \mathrm{~mm}$ diameter, $50 \mathrm{~cm}$ outlet and inlet lengths, $15 \mathrm{~cm}$ curvature radius, and $78 \mathrm{~mm}$ pitch length (the distance between the axial lines of the inlet and outlet tubes). The liquid water with $20^{\circ} \mathrm{C}$ as initial temperature, spherical solid particles with $2650 \mathrm{~kg} / \mathrm{m}^{3}$ density, and the Rosin-Rammler size distribution (with 10 different particles sizes with 100, 250, and $400 \mu \mathrm{m}$ diameters for minimum, average, and maximum diameter sizes, respectively) have been entered into steel pipes (with $7800 \mathrm{~kg} / \mathrm{m}^{3}$ density). For enhancing the convergence rate in the numerical solution, structured grids have been used to produce mesh configuration for relevant geometries. 
To overcome complexity issues in the curved sections of pipes, the local densities of adopted meshes have been increased smoothly.

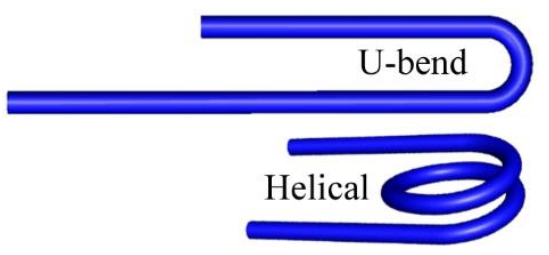

Fig. 1. Defined U-bend and helical pipes geometries.

The Euler-Lagrangian method has been used for steady-state simulation of the fluid and particle flows in this model. The continuous phase, i.e. liquid fluid, the flow has been simulated by solving the continuity, Navier-Stokes and Realizable k- $\varepsilon$ equations and the motions of the particles, as the discrete phase, have been simulated using Newton's second's law, as follows (Ansys I. FLUENT 19 User's Guide 2018, Shih 1995):

$$
\begin{gathered}
\frac{\partial\left(p u_{i}\right)}{\partial x_{i}}=0 \\
\frac{\partial\left(\rho u_{i} u_{j}\right)}{\partial x_{j}}=-\frac{\partial p}{\partial x_{i}}+\frac{\partial}{\partial x_{j}}\left[\left(\mu+\mu_{t}\right)\left(\frac{\partial u_{i}}{\partial x_{j}}+\frac{\partial u_{j}}{\partial x_{i}}\right)\right]+\rho g_{i}+S_{M} \\
\frac{\partial\left(\rho k u_{j}\right)}{\partial x_{j}}=\frac{\partial}{\partial x_{j}}\left[\left(\mu+\mu_{t}\right) \frac{\partial k}{\partial x_{j}}\right]+G_{k}+G_{b}-\rho \varepsilon+S_{k} \\
\frac{\partial\left(\rho \varepsilon u_{j}\right)}{\partial x_{j}}=\frac{\partial}{\partial x_{j}}\left[\left(\mu+\frac{\mu_{t}}{1.2}\right) \frac{\partial \varepsilon}{\partial x_{j}}\right]+\rho S_{s}\left\{\max \left[0.43, \frac{\sqrt{2 S_{i j} S_{i j}} \frac{k}{s}}{5+\sqrt{2 S_{i j} S_{i j}} \frac{k}{s}}\right]\right\} \\
\frac{d \vec{u}_{p}}{d t}=\vec{F}_{D}+\vec{F}_{P}+\vec{F}_{V M}+\vec{F}_{B}
\end{gathered}
$$

where $P, g, x_{i}, u_{i}, u_{p}, \rho, \mu, v$ and $\mu_{t}$ are static pressure, gravitational acceleration, a component of the direction vector in the Cartesian system, a component of the fluid velocity vector, particle velocity vector, fluid density, fluid static viscosity, fluid dynamic viscosity and flow turbulent viscosity $\left(\mu=0.09 \rho \frac{k^{2}}{\mu}\right)$, respectively. $G_{k}$ and $G_{b}$ are the turbulence and kinetic energy generation rates due to the mean of the fluid velocity gradient $\left(G=2 \mu_{t} S_{i j} S_{i j}\right.$, where $\mathrm{S}$ is the strain tensor) and buoyancy ( $G_{b}=-\frac{g_{i} \mu_{t}}{0.85 \rho}\left(\frac{\partial \rho}{\partial T}\right)_{P} \frac{\partial T}{\partial x_{i}}$, where $T$ is the fluid temperature), respectively. 
$F_{D}, F_{P}, F_{V M}$, and $F_{B}$ are the drag $\left(\vec{F}_{D}=\frac{3 \rho C_{D}\left|\vec{u}-\vec{u}_{p}\right|}{4 \rho_{p} d_{p}}\left(\vec{u}-\vec{u}_{p}\right)\right)$, where $\rho_{p}$ and $d_{p}$ are the particle density and diameter, respectively, and $C_{D}$ is the drag force that has been calculated using the Morsi and Alexander correlation for spherical particles, $C_{D}=a_{1}+\frac{a_{2}}{\mathrm{Re}_{s}}+\frac{a_{2}}{\mathrm{Re}_{s}^{2}}$, which is a function of $\operatorname{Re}_{s}=\frac{\rho d_{p}\left|u_{p}-u\right|}{\mu}$ and has triple constants, i.e. $a_{1}, a_{2}$ and $a_{3}$ (Morsi and Alexander 1972)), pressure gradient $\left(\overrightarrow{F_{P}}=\frac{\rho}{\rho_{p}} \frac{\partial P}{\partial x_{i}}\right)$, virtual mass $\left(\overrightarrow{F_{V M}}=\frac{\rho}{2 \rho_{p}} \frac{d\left(\vec{u}-\overrightarrow{u_{p}}\right)}{d t}\right)$ and buoyance forces $\left(\overrightarrow{F_{B}}=\frac{g}{\rho_{p}}\left(\rho_{p}-\rho\right)\right)$, respectively.

The continuous phase affects the discrete phase by the mentioned forces and the particles also affect the fluid flow by reducing the turbulence of this liquid flow. The two-way coupling method has been used for considering this fluid-particle interaction. The fluid momentum changes due to the particle's effects $\left(S_{M}=\sum\left(F_{D}+F_{P}+F_{V M}+F_{B}\right) M_{p} \Delta t\right.$, where $M_{p}$ is the mass transfer of the solid particles and $\Delta t$ is the time step of the calculations). It is assumed that the local fluctuations of the fluid flow velocity (i.e. $u_{i}^{\prime}$ ) be isotropic and the particle-eddy interaction model (discrete random walk model, $u_{i}^{\prime}=\zeta \sqrt{\frac{2 k}{\varepsilon}}$, where $\zeta$ is a random value with a normal distribution) (Gosman and Ioannides 1983) has been used for considering the effects of the fluctuations of the fluid velocity on the motion of the particles. The two-way coupling between the eddies and particles has been considered using the defined source terms in the k- $\varepsilon$ equations (i.e. $S_{k}$ and $S_{\varepsilon}$ ). The particle-wall rebound model (Grant and Tabakofft 1975) has been used to calculate the reflect angle $\left(90^{\circ}\right)$ and velocity of particles after impacting the tube wall ( $\frac{u_{p n}^{\text {out }}}{u_{p n}^{\text {in }}}=0.993-1.76 \alpha+1.56 \alpha^{2}-0.49 \alpha^{3}$ and $\frac{u_{p n}^{\text {out }}}{u_{p n}^{\text {in }}}=0.988-1.66 \alpha+2.11 \alpha^{2}-0.67 \alpha^{3}$, where $u_{p n}^{\text {in }}$, $u_{p n}^{i n}, u_{p n}^{i n}$ and $u_{p n}^{i n}$ are a normal and tangential component of particles velocity vector before and after impacting the tube wall, and $\alpha$ is the impact angle). The Oka erosion model (Banakermani et al. 2018; Vieira et al. 2016) has been used for calculating the erosion ratio of the tube wall due to the particles impactions

$E R=65 \times 10^{9} \rho_{w}(\sin \alpha)^{0.71 H_{V}^{0.14}}\left[1+H_{V}(1-\sin \alpha)\right]^{2.4 H_{V}^{-0.94}} H_{V}^{-0.12}\left(\frac{u_{p}}{104}\right)^{2.3 H_{V}^{0.038}}\left(\frac{d_{p}}{326}\right)^{0.19}, \quad$ where $\rho_{w}$ is the wall density and $H_{V}$ is the Vicker's hardness, which is $1.8 \mathrm{GPa}$ for steel). The near-wall fluid flow has been modeled using the scalable wall function of the $k$ - $\varepsilon$ model. Different regions of the boundary layer (i.e. viscous sublayer, the buffer layer, and fully turbulent region) of this turbulent fluid flow have been classified using the dimension wall distance $\left(y^{+}=\frac{y \sqrt{\frac{t_{w}}{\rho}}}{v}\right.$, where $\tau_{w}$ is the shear stress of the fluid on the tube wall). For numerical solving of the presented equations, the SIMPLEC algorithm has been used. Constant fluid flow velocity at the inlet, constant pressure at the outlet, and no-slip condition at the tube wall were the defined boundary conditions for the continuous phase. The escape boundary condition at both of the inlet and outlet and reflect conditions at the tube wall were defined for the discrete phase. 


\section{Results and Discussions}

First, the grid study has been presented to show the mesh independency of this numerical solution illustrated in Figure 2. For this purpose, the U-bend pipe has meshed with 380000, 720000, and 910000 calculation cells. Furthermore, 400000, 980000, and 1110000 calculation cells have been used for the helical pipe. As seen in Figure 2, 720000 and 980000 cells have suitable accuracies and calculation times. Therefore, these meshes were used for this simulation because the maximum difference value of results between selected mesh cell numbers and the higher one is around $4 \%$. In the second step, the predictions of the developed model have been compared with the experimental and numerical calculation results of the previous study of Vieira et al. (2016) for validating the accuracy of these predictions. They measured the erosion rate in a 90o elbow with $76.2 \mathrm{~mm}$ diameter, $1 \mathrm{~m}$ entrance length, and $0.6 \mathrm{~m}$ outlet length using the ultrasonic tests. Figure 3 shows contours of the model predictions for erosion rate and Table 1 presents the results of this comparison. These cases had similar gas flow velocities and also particles diameter, but, had different particles mass flowrates. This comparison approves the ability of this model to simulate the erosion of solid particles in such fluid flows.

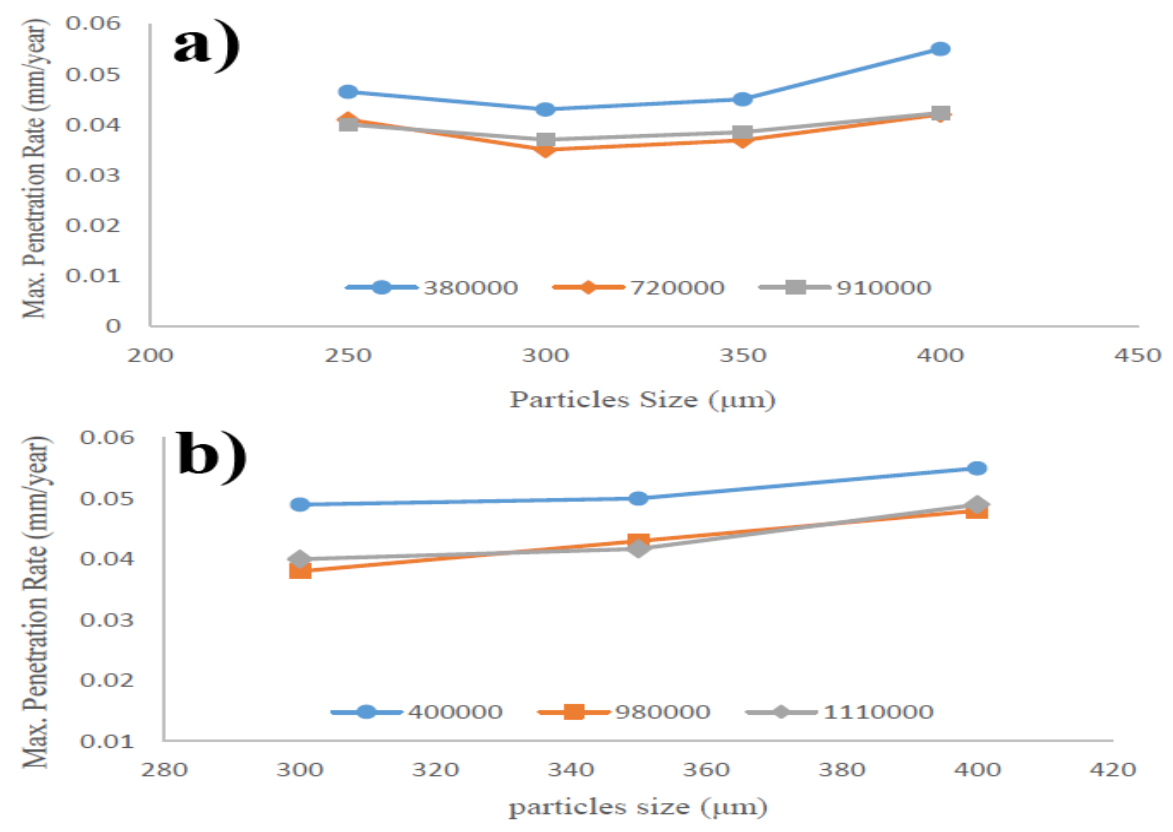

Fig. 2. Mesh study for the a) U-bend and b) helical pipes. 

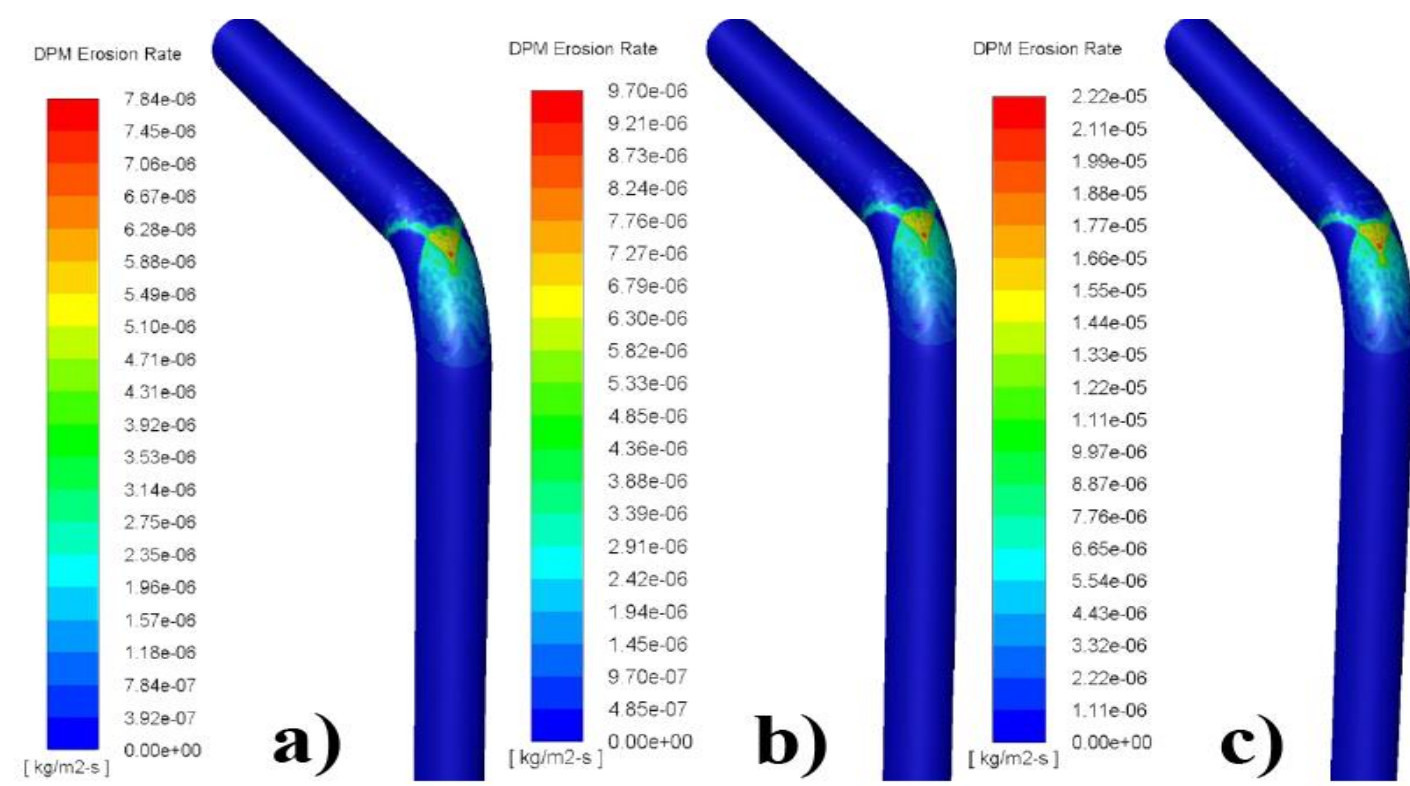

Fig. 3. Contours of the model predictions for erosion in the presented cases in Table 1

which had similar gas flow velocities and also particles diameter (gas velocity $15 \mathrm{~m} . \mathrm{s}^{-1}$, particle diameter $300 \mu \mathrm{m}$ ), but, had different particles mass flowrates.( a) Particles mass flowrate 154 $\mathrm{kg} \mathrm{day}^{-1}$, maximum penetration rate $22.1 \mathrm{~mm} . \mathrm{day}^{-1}$. b) Particles mass flowrate $192 \mathrm{~kg}^{-\mathrm{day}}{ }^{-1}$, maximum penetration rate $19.3 \mathrm{~mm} \cdot \mathrm{day}^{-1}$. c) Particles mass flowrate $452 \mathrm{~kg}$. $\mathrm{day}^{-1}$, maximum penetration rate $58.5 \mathrm{~mm} . \mathrm{day}^{-1}$ )

\begin{tabular}{|c|c|c|c|c|c|c|}
\hline Case & Gas & Particle & Particles & Maximum & Vieira & Present \\
& velocity & diameter & mass & penetration & simulation & simulation \\
& $\left(m \cdot s^{-1}\right)$ & $(\mu m)$ & flowrate & rate & $\left(\right.$ mm.day $\left.^{-1}\right)$ & $\left(\right.$ mm.day $\left.^{-1}\right)$ \\
\hline$a$ & 15 & 300 & 154 & 22.1 & 30.3 & 30.95 \\
\hline b & 15 & 300 & 192 & 19.3 & 37.5 & 38.28 \\
\hline $\mathrm{c}$ & 15 & 300 & 452 & 58.5 & 87.4 & 87.6 \\
\hline
\end{tabular}

Table 1. Comparing the predictions of the presented model with the obtained results by Vieira et al. (2016).

The redirection of liquid flow inside the U-bend pipe has an essential effect on the motion of solid particles. As shown in Figure 4, for small particles with $50 \mu \mathrm{m}$ diameter, the strong secondary liquid flow in the bend leads these particles toward the bend's inside curvature and 
causes severe erosion in this area. For larger particles $(300 \mu \mathrm{m}$ diameter $)$, the importance of this secondary liquid flow on the particles' motion has been decreased because of the importance of the inertial force of these particles. The mentioned force causes a direct motion for these particles in the U-bend, and any erosion of this pipe's outside curvature wall by these particles. It is also clear that the large particles' extent of the tube wall's impact was more significant than the small particles. Fore middle sizes of solid particles, i.e. with $150 \mu \mathrm{m}$ average diameter, a combination of these effects have been observed in this bend. Therefore, this particle size has a width scale and low penetrated erosion on both sides of this bend. It is also observed that solid particles with a regular size distribution between 50 to $400 \mu \mathrm{m}$ diameters have a width erosion area inside this U-bend due to the different forces affecting these particles. The reflected particles impact the tube wall at the mentioned area in this Figure with lower inertia due to the reduction of their velocities in the first impaction.

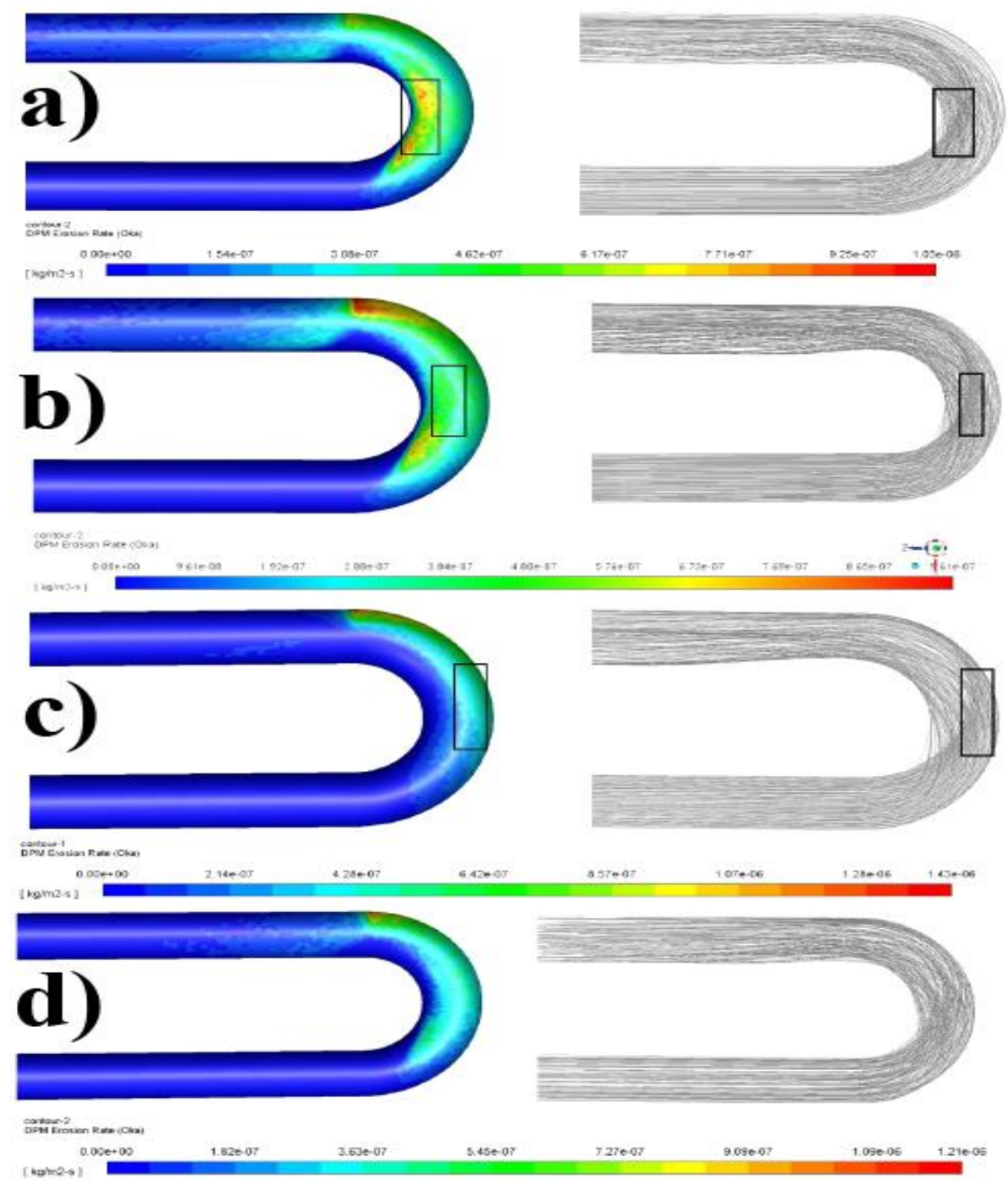

Fig. 4. The particles tracing and erosion areas of particles with a) $50 \mu \mathrm{m}$, b) $150 \mu \mathrm{m}$, c) $300 \mu \mathrm{m}$ and d) Rosin-Rammler size distribution, in the U-bend pipe. 
In the helical pipe, attending to the fluid flows around a central axis, a centrifugal force leads the fluid flow and also solid particles toward the outside curvature of this pipe and causes more erosion on the wall of this tube in these areas. Figure 5 shows the particle tracing and also the erosion areas in this pipe. As seen in this Figure, there is no erosion on the inside curvature wall of this pipe. A high erosion rate of solid particles inside the first section of the outlet length of this tube, due to the mentioned circular flow in the previous section of this pipe, has been observed. It is also observed that gravity has no important effect on the fluid flow and also the erosion of solid particles inside this pipe.
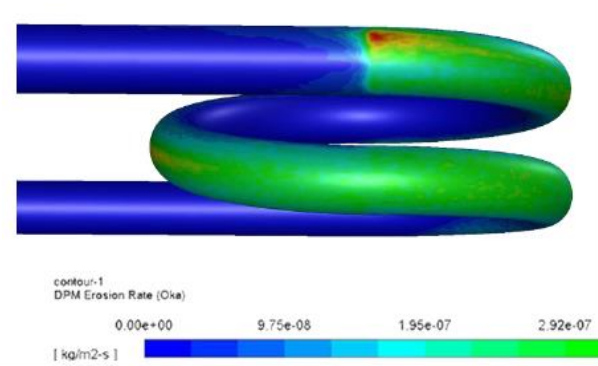
$195 e-07$ $2.92 \mathrm{e} \cdot 07$ $3.900-07$

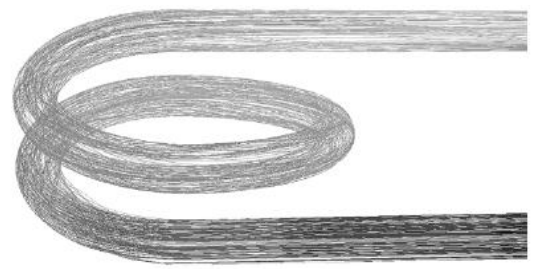

Fig. 5. The particle tracing and erosion areas of particles with Rosin-Rammler size distribution in the helical pipe.

Figure 6 shows the effects of inlet water velocity increment on the penetration rate of the solid particles in the pipes inside the walls. Increasing the fluid velocity increases the inertial force entered particles, increases the extents of their impacts on the wall, and increases their penetration rate, consequently. It is observed that the non-uniform size distribution of solid particles has a lower penetration rate and a wider erosion area than the uniform particles due to the effects of different forces on these particles. Figure 7 shows the effects of the mass flow rate of solid particles on the penetration rate of these particles on the inside walls of U-bend and helical pipes. Increasing the mass flow rate of the particles increases the number of particles that impact the walls of the pipe and increases their penetration rate, consequently.

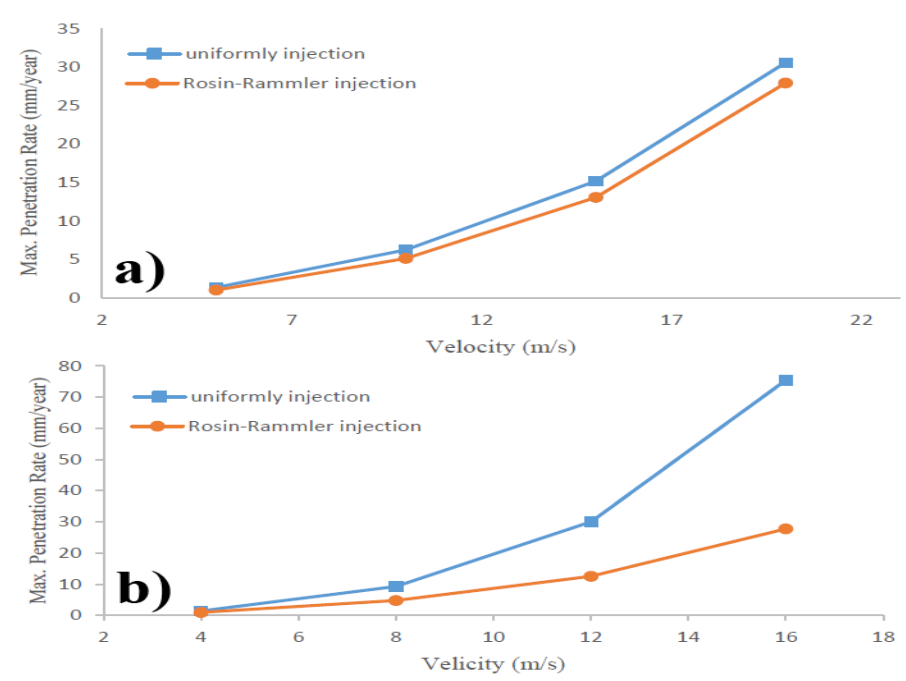

Fig. 6. Effects of inlet water velocity increment on the penetration rate of the solid particles in the pipes inside walls of a) U-bend and b) helical pipes. 

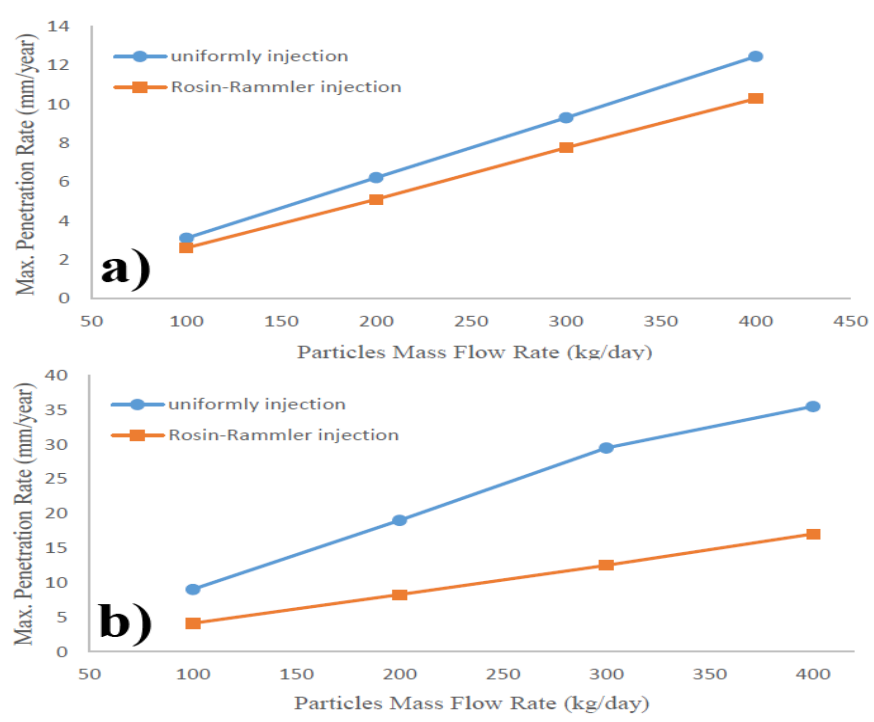

Fig. 7. Effects of mass flowrate of solid particles on the penetration rate of solid particles on the inside walls of a) U-bend and b) helical pipes.

The effects of particle size on their penetration rate have been investigated in Figure 8. As previously mentioned, small particles experience different dominant forces in this flow. This is the main reason for their different penetration rates in these pipes. Figure 9 shows the effects of fluid temperature on the penetration rate of solid particles in these pipes. It is assumed that the temperature profile in the fluid flow is uniform and the effects of this temperature on the density and viscosity of liquid fluid have been considered in this comparison. As seen in this Figure, the fluid temperature increment increases the penetration rate of particles due to the increment of the liquid viscosity and density and increasing the energy of impactions of these particles to the walls, consequently.

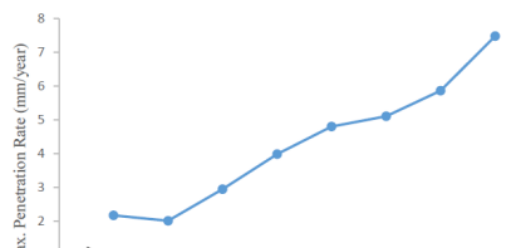

a)

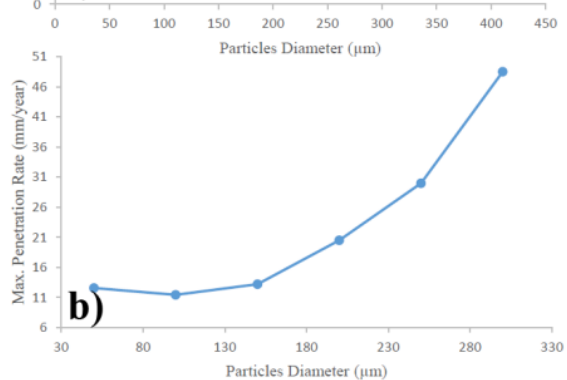

Fig. 8. Effects of particle size on the penetration rate of these particles on the inside walls of a) U-bend and b) helical pipes. 


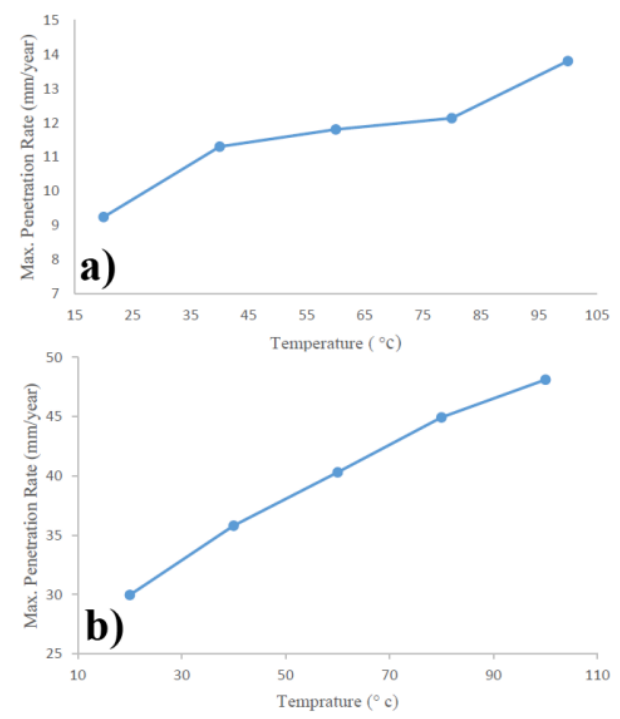

Fig. 9. Effects of fluid temperature on the penetration rate of solid particles on the inside walls of a) U-bend and b) helical pipes.

Figure 10 compares the penetration rate of solid particles with different densities on the Ubend and helical pipes walls. It is clear that increasing the density of solid particles increases the extent of their impactions to the walls of the pipe and increases their penetration rate, as a result. Figure 11 shows the effects of the R/D ratio on the penetration rate of particles. Attending to the constant diameter of the modeled pipes, a greater R/D ratio means a more length of the curved section of these pipes and simpler flows of liquid fluid and solid particles inside these pipes. It is the reason for the observed low erosion ratio of particles in the pipes with a high R/D ratio.

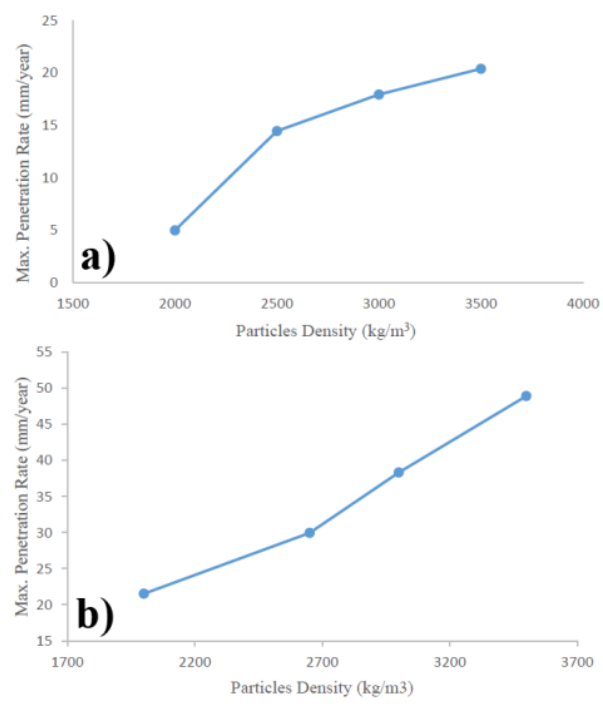

Fig. 10. Comparing the penetration rate of solid particles with different densities on the a) Ubend and b) helical pipes walls. 


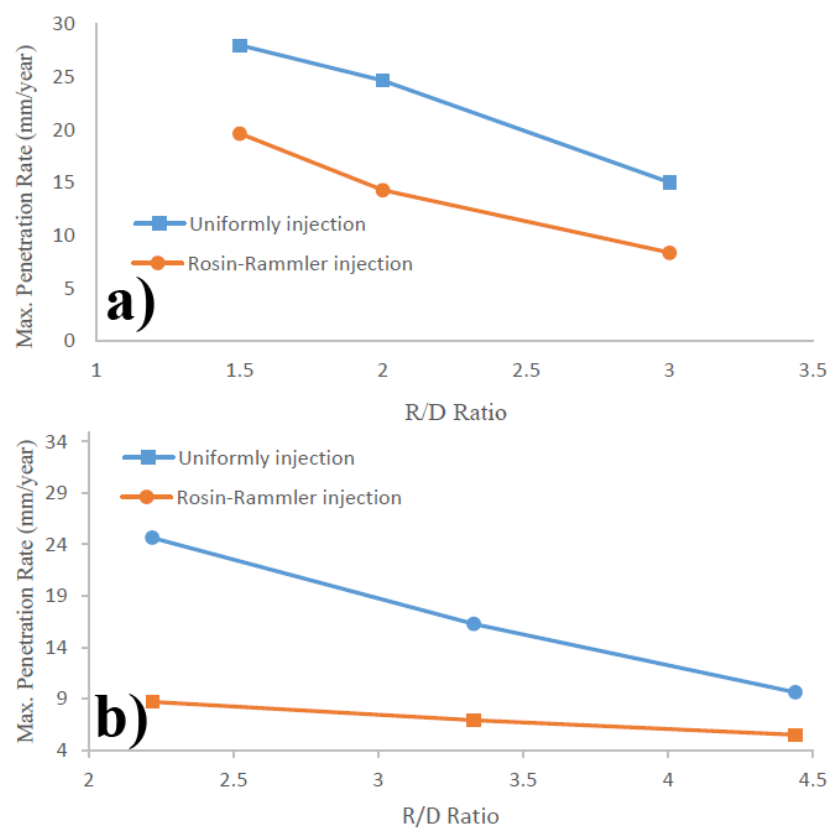

Fig. 11. Effects of R/D ratio on the penetration rate of solid particles on the inside walls of a) Ubend and $b$ ) helical pipes.

\section{Conclusions}

In this study, the computational fluid dynamic was used to simulate the liquid fluid flow and solid particle motion inside U-bend and helical pipes, using the Euler-Lagrangian method, two-way coupling interaction between the liquid flow and solid particle, and also Oka erosion model. The accuracy of the predictions of this model was confirmed using the experimental results of a previous study. Finally, the effects of different factors, such as temperature and velocity of liquid flow, the mass flow rate of solid particles, density, and diameter of these particles, and the R/D ratio were investigated using the developed model.

It has resulted in redirection of liquid flow inside the U-bend pipe having an important effect on the motion of solid particles. Small particles experienced a strong secondary liquid flow in the bend and moved toward the inside curvature of the bend and caused serious erosion in this area. But, larger particles experienced a strong inertial force and moved on a direct path line in the Ubend section and caused much erosion of the outside curvature wall of this pipe. It is also concluded that the extent of impactions of large particles to the tube wall was greater than the small particles. A centrifugal force leads the fluid flow and solid particles toward the outside curvature of the helical pipe and caused more erosion on the wall of this tube in these areas. Increasing the fluid velocity increased the inertial force entered particles, increased the extents of their impacts to the wall, and increased their penetration rate, consequently. The results suggest that the non-uniform size distribution of solid particles had a lower penetration rate and a wider erosion area than the uniform particles due to the effects of different forces on these particles. Increasing the mass flow rate of solid particles increased the number of particles that impacts the walls of the pipe and increased their penetration rate, consequently. The fluid temperature increment increased the penetration rate of particles due to the increment of the liquid viscosity and density and increasing the energy of impactions of these particles to the walls, consequently. 
Increase in the density of solid particles increased the extent of their impactions to the walls of the pipe and increased their penetration rate, as a result. In a constant diameter of the modeled pipes, a greater R/D ratio had a more length of the curved section of these pipes and a simpler flows of liquid fluid and solid particles inside these pipes. Therefore, particles had a low erosion ratio in the pipes with a high $\mathrm{R} / \mathrm{D}$ ratio.

\section{References}

Ahlert K. (1994). Effect of Particle Impingement Angle and Surface Wetting on Solid Particle Erosion of AISI 1018 Steel (M.S. thesis), The University of Tulsa, Tulsa, USA.

Ansys I. FLUENT 19 User's Guide. (2018). Modeling basic fluid flow. Chapter 9 (2-4) and Modeling Discrete Phase. Chapter 22.

Antonio C, Duarte R, De Souza FJ, and Fagundes V (2015). Numerical investigation of mass loading effects on elbow erosion, Powder Technol. 283, 593-606.

Banakermani MR, Naderan H, and Saffar-Avval M (2018). An investigation of erosion prediction for $15^{\circ}$ to $90^{\circ}$ elbows by numerical simulation of gas-solid flow, Powder Technol. 334, 926.

Bozzini B, Ricotti ME, Boniardi M, and Mele C (2003). Evaluation of erosion - corrosion in multiphase flow via CFD and experimental analysis, Wear, 255, 237-245.

Burson-Thomas C B, and Wood RJK (2017). Developments in Erosion-Corrosion over the Past 10 Years, J. Bio- Tribo-Corrosion. 3(2), 14-15.

Chen J, Wang Y, Li X, He R, Han S, and Chen Y (2015). Reprint of Erosion prediction of liquidparticle two-phase flow in pipeline elbows via CFD-DEM coupling method, Powder Technol. 282, 25-31.

Chen X, McLaury BS and Shirazi S. A (2004). Application and experimental validation of a computational fluid dynamics (CFD)-based erosion prediction model in elbows and plugged tees, Comput. Fluids. 33(10), 1251-1272.

Fan J, Yao J, Zhang X, and Cen K (2001). Experimental and numerical investigation of a new method for protecting bends from erosion in gas-particle flows, 251, 853-860.

Finnie I. (1960). Erosion of surfaces, Wear. 3, 87-103.

Gosman A D and loannides E (1983). Aspects of Computer Simulation of Liquid Fueled Combustors, J. Energy, 7(6), 482-490.

Grant G. and Tabakofft W (1975). Erosion Prediction in Turbomachinery Resulting from Environmental Solid Particles, J. Aircraft. 12(5), 471-477.

Mazumder Q H, Shirazi S A, McLaury B S, Shadley J R and Rybicki E F (2005). Development and validation of a mechanistic model to predict solid particle erosion in multiphase flow, Wear. 259(1), 203-207.

McLaury BS (1996). Predicting solid particle erosion resulting from turbulent fluctuations in oilfield geometries (Ph.D. Thesis), University of Tulsa, Tulsa, USA.

Meng HC, and Ludema KC (1995). Wear models and predictive: their form and content, Wear. 183, 443- 457.

Morsi S A and Alexander A J (1972). An investigation of particle trajectories in twophase flow systems, J. Fluid Mech. 55(2), 193-208.

Pereira G C, de Souza F J, and de Moro Martins D A (2014). Numerical prediction of the erosion due to particles in elbows, Pow. Tech. 261, 105-117.

Salama M M (2000). An Alternative to API 14E Erosional Velocity Limits for Sand Laden Fluids, J. Energy Resour. Technol. 122(2), 71-72.

Shih T H, Liou WW, Shabbir A, Yang Z, and Zhu J (1995). A new k- $\varepsilon$ eddy viscosity model for high reynolds number turbulent flows, Comput. Fluids. 24(3), 227-238. 
Solnordal C B, and Wong C Y (2015). An experimental and numerical analysis of erosion caused by sand pneumatically conveyed through a standard pipe elbow, Wear, 336, 43-57.

Vieira RE, Mansouri A, McLaury B S and Shirazi S A (2016). Experimental and computational study of erosion in elbows due to sand particles in air flow, Powder Technol. 288, 339-353.

Zhang H, Tan Y, Yang D, Trias FX, Jiang Sh, Sheng Y, and Oliva A (2012). Numerical investigation of the location of maximum erosive wear damage in elbow: Effect of slurry velocity, bend orientation and angle of elbow, Powder Technol. 217, 467-476.

Zhang Y, Reuterfors E P, McLaury B S, Shirazi S A, and. Rybicki E F(2007). Comparison of computed and measured particle velocities and erosion in water and air flows, Wear 263(1), 330-338. 